\title{
Stabilization of Black Cotton Soil with Groundnut Shell Ash
}

\author{
R. Premkumar ${ }^{1, a^{*}}$, B. Subha1 ${ }^{1}$ S. Pattu Sandhiya ${ }^{1}$, K. Shankar Narayanan² \\ ${ }^{1}$ School of Environmental and Construction Technology, Department of Civil Engineering, \\ Kalasalingam Academy of Research and Education, Krishnankoil, Tamil Nadu, India \\ ${ }^{2} \mathrm{~F}$ Geotechnical Engineer, Ayothi Consultancy, Rajapalayam, Tamil Nadu, India \\ aprem.ce@gmail.com, * corresponding author
}

\begin{abstract}
Keywords: California Bearing Ratio (CBR), Unconfined Compressive Strength (UCS), Stabilization, Groundnut Shell Ash (GSA), Black Cotton Soil
\end{abstract}

\begin{abstract}
The analysis of GSA for the stabilization of soil samples is the subject of this research paper. In recent years, soil stabilization techniques have been effective in improving the shear strength parameters of poor soils. GSA is a naturally occurring substance that causes human health and environmental issues. Physical properties of soil were calculated, including Atterberg's limits, compaction characteristics, and strength characteristics of virgin soil samples. GSA was applied to the soil in various percentages ( 2 to 10 percent). The soil sample's intensity increased up to $6 \%$ before decreasing. It is clear that $6 \%$ of GSA to the soil is an optimum percentage and it leads to an increase in shear strength and bearing capacity in expansive soil.
\end{abstract}

\section{Introduction}

In this high-level period of science and innovation, man has made fast walks in all fields since the old ages. Directly from the dim ages till the current data age, man has developed significantly and has attempted to come around a wide range of issues experienced. From a designing perspective, particularly from a geotechnical viewpoint, land use for improvement work has brought to the front, the issue of intense land lack [1]. This has prompted the recovery of unusable land for advancement exercises. Ground improvement innovation has been the main thrust that has achieved this insurgency in the recovery of unusable land, which has lead to abrupt spray informative exercises. Likewise, this innovation, however gainful severally, had natural effects. With quick urbanization and industrialization, this innovation turned into the main thrust for all land recovery work. With the rising utilization of a portion of these procedures, for example, concrete grouting, lime segments, and soon, the effect on the climate came to be gradually perceived [2]. Regular materials and their utilization in ground improvement is one such territory of potential and guarantee.

Black cotton soil is clay soil with a lot of space. Clay poses a significant challenge to building construction due to its low shear strength and strong bulge (swelling) characteristics [3]. To regulate this action, the worthy cohesive soil reacts with chemical compounds or any other suitable material that can change its engineering actions. The study's goal was to increase soil strength while lowering construction costs by using locally available materials in the most efficient way possible.GSA has self-hardening and bonding characteristics, so it will help the soil particles to bond with each other. Then it became dense automatically density of the soil gets increased. Researchers Robert, et.al. In this paper, they are using fly ash, rice husk ash for stabilizing soil effectively [4]. It is much more effective but economically it cost more. It is economically not suitable. In the current world, the research work is done in geotechnical Engineering and materials used in construction. Misra, et. are using fly ash, bagash, blast furnace slag, etc. because it is 
economical and environmentally friendly[5-6]. It gives good strength. Replacement did for fully (or) partially.

\section{Materials}

Figure 1 depicts the soil sample used in the ongoing investigation. Necessary tests were used to determine the strength characteristics of soil specimens. A soil sample was taken in Rajapalayam, Virudhunagar District. The samples were taken at a depth of 2 meters and are disturbed. Before the experiments, it was air-dried and pulverized.

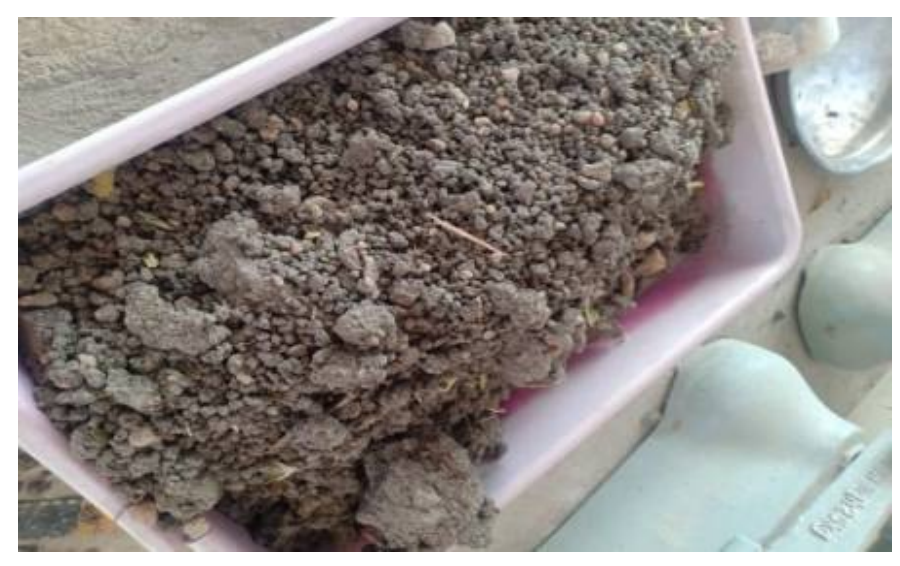

Figure 1.Preparation of Specimen

\section{Groundnut shell ash}

Groundnut shells were spread on the ground and air-dried for 2 days to encourage simple processing. After air-drying the groundnut shell was physically broken and processed into ordinary temperature $\left(37^{\circ} \mathrm{c}\right)$ debris structures shown in figure 2. The properties of groundnut shell ash are Groundnut shell ash is unscented and Groundnut shell ash contains $\mathrm{CaO}, \mathrm{Al}_{2} \mathrm{O}_{3}, \mathrm{SiO}_{2}$, $\mathrm{Fe}_{2} \mathrm{O}_{3}, \mathrm{MnO}$, and $\mathrm{MgO}$.

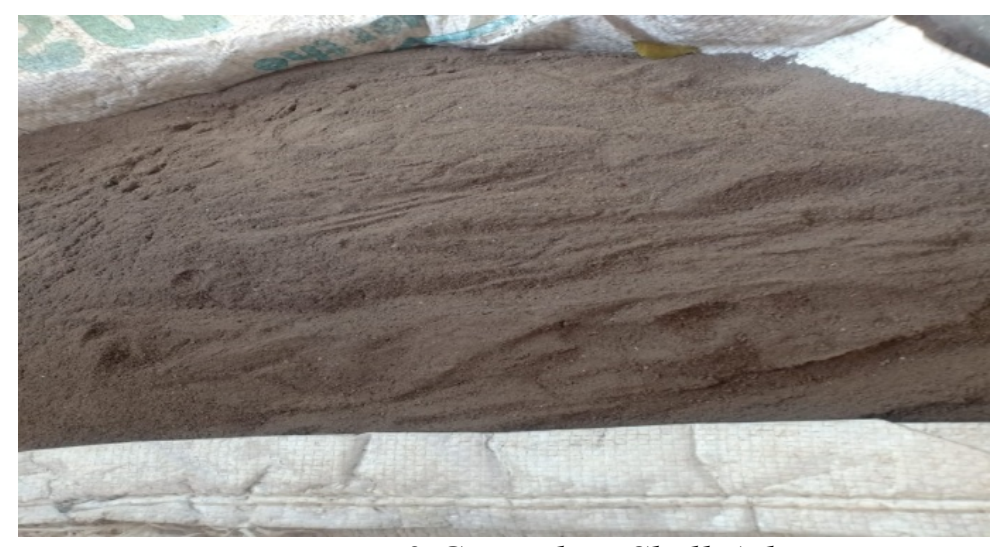

Figure 2.Groundnut Shell Ash 


\section{Experimental Investigation}

The various tests were carried out on virgin soil specimens following IS Standard (IS: 2720). Primarily, the black cotton soil that had been prepared was examined. The soil was then combined with groundnut shell ash to measure its compaction characteristics, which included determining the optimum moisture content and maximum dry density of the specimen using a standard proctor test, as well as the specimen's strength characteristics using CBR and UCC tests.

\section{Results and Discussion}

Table 1.Virgin soil specimen engineering properties

\begin{tabular}{clc}
\hline S.No & \multicolumn{1}{c}{ Specification } & Results \\
\hline 1 & Free swell (\%) & 65 \\
2 & Liquid limit (\%) & 58.4 \\
3 & Plastic Limit (\%) & 20.34 \\
4 & Plasticity index (\%) & 38.04 \\
5 & Shrinkage Limit (\%) & 6 \\
6 & Specific gravity (\%) & 2.75 \\
7 & Maximum dry density (g/cc) & 1.64 \\
8 & Optimum moisture content (\%) & 15 \\
9 & CBR value (\%) & 5.71 \\
10 & UCC value (kN/m2) & 125 \\
& Grain size distribution & 27.3 \\
11 & Sand (\%) & 72.7 \\
12 & Silt + Clay (\%) & $\mathrm{CH}$ \\
\hline
\end{tabular}




\section{Varying percentage of GSA}

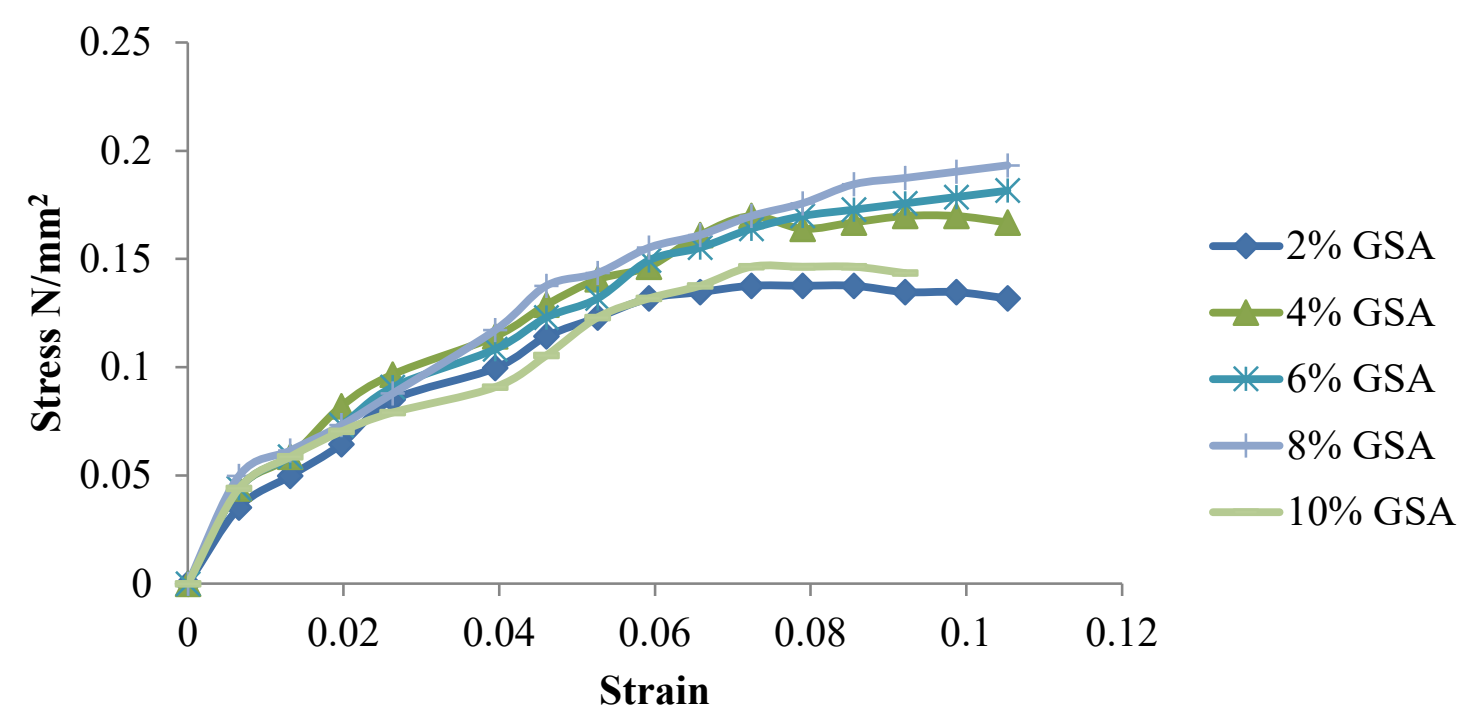

Figure 3.Stress-Strain curve for soil with GSA

The virgin soil specimen's properties were tabulated in Table 1. The free swell percentage was $65 \%$ which is higher than $50 \%$ so it is identified to be rapidly expansive depends on IS-2720(part XL)-1997. The specimen's shrinkage limit is $6 \%$, which is lower than 11 percent, and it has a large swelling capacity, according to IS: 2720 (part6). The BC soil's normal basic gravity is (2.65-2.90). The BC used in the experiment had a test outcome of 2.75 percent. For the plain soil sample, the maximum dry density was $1.64 \mathrm{~g} / \mathrm{cc}$ and the optimum moisture content was $15 \%$. The virgin soil sample has a CBR value of 5.71 percent (According to IS-2720 part 16, the fair CBR value of the mid soil is 4-6). The virgin soil specimen's unconfined compressive intensity is $0.125 \mathrm{~N} / \mathrm{mm}^{2}$. The UCC values are in the middle of $\left(0.100-0.200 \mathrm{~N} / \mathrm{mm}^{2}\right)$ which denotes the soil's stiff consistency. According to the test result liquid limit of the specimen is $58.4 \%$ and plasticity index $=(\mathrm{LL}-\mathrm{PL})=$ 38.04. It is beyond A-Line in the plasticity chart. From the results, the soil specimen is separated as highly compressible clay $(\mathrm{CH})$.

Table 2.UCC values of GSA with soil specimen

\begin{tabular}{cc}
\hline $\begin{array}{c}\text { Differing percentage of } \\
\text { Groundnut Shell Ash\% }\end{array}$ & $\begin{array}{c}\mathbf{q u}_{\mathbf{u}} \\
\mathbf{N} / \mathbf{m m}^{\mathbf{2}}\end{array}$ \\
\hline 0 & 0.125 \\
2 & 0.127 \\
4 & 0.154 \\
6 & 0.161 \\
8 & 0.173 \\
10 & 0.135 \\
\hline
\end{tabular}

The difference in strain vs. stress of the different percentages of Groundnut Shell Ash with soil specimen is shown in Figure 3. Virgin soil specimen has a UCC value of $0.125 \mathrm{~N} / \mathrm{mm} 2$. After 
combining $8 \%$ off GSA, it increased to $0.173 \mathrm{~N} / \mathrm{mm} 2$. Due to the mixing of GSA and the soil particle, the intensity of the soil initially increases as the percentage of GSA increases. Later on, as the volume of GSA increases, the intensity decreases. With an increase in ash content, the ash did not properly mix with the soil, resulting in poor ash dispersion in the soil matrix and decreased load transfer efficiency. The optimal GSA percentage has been determined to be $8 \%$. The UCC value decreases when 10\% GSA is combined. As a result, an increase in GSA content reduces the soil's intensity. It is due to the fact that stray-oriented ash recharges the soil particles on its own.

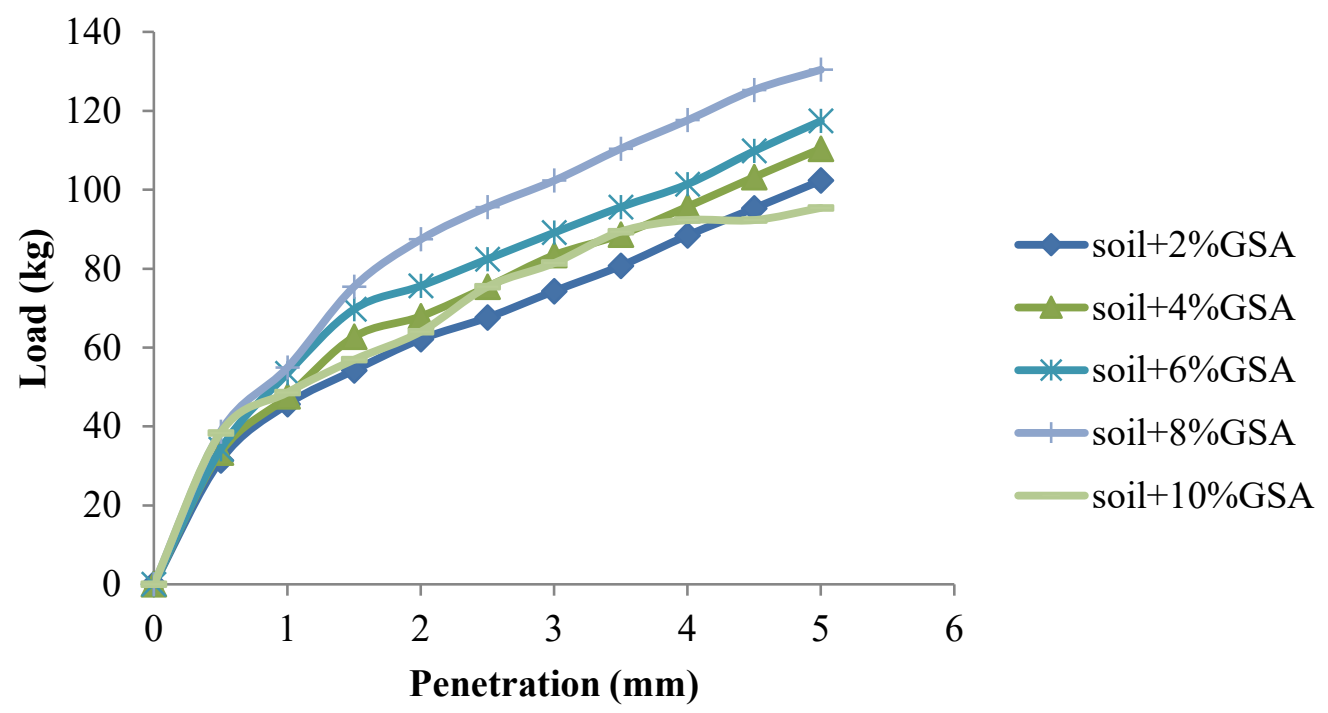

Figure 4: Load-penetration curve for soil with GSA

Table 2 shows the effect of UCC strength on soil with GSA. It shows that the strength of the soil is rapidly increasing after a combination of the GSA in percentage, which is due to the soil and GSA interchange. When the quantity of GSA is getting increased, it leads to ash interchange which reduces the strength of the soil. Also, $8 \%$ of GSA, the strength of the soil increases from $0.125 \mathrm{~N} / \mathrm{mm}^{2}$ to $0.173 \mathrm{~N} / \mathrm{mm}^{2}$, which is identified to be $54.67 \%$ from the virgin soil specimen. Besides $10 \%$ GSA with soil specimen, the strength is higher than virgin soil specimen but lower than $8 \%$ GSA. This concludes $8 \%$ off GSA to be the optimum percentage.

Table 3.CBR test results of soil sample with the differing percentage of GSA

\begin{tabular}{cc}
\hline $\begin{array}{c}\text { Differing percentage of } \\
\text { GSA }\end{array}$ & CBR(\%) \\
\hline 0 & 5.71 \\
2 & 6.75 \\
4 & 7.27 \\
6 & 7.70 \\
8 & 8.31 \\
10 & 7.27 \\
\hline
\end{tabular}

Figure 4 depicts the load penetration of soil with higher GSA percentages. With a high GSA, the CBR value is high. Figure 5 shows the optimum GSA value for obtaining the full CBR value at $2.5 \mathrm{~mm}$ penetration. The combination of GSA and clayey soil results in an improvement in CBR 
value. It is more capable of changing the soil stress along with the ash due to better associate enhancement with mid soil particles and the ash permit. Despite this, the rise in an ash-ash associate may be to blame for the decrease in CBR values above the optimum ash content. After increasing the percentage of GSA above $8 \%$, the load penetration curve of the soil specimen decreases.

\section{Development in UCC strength of soil Stabilized with}

GSA

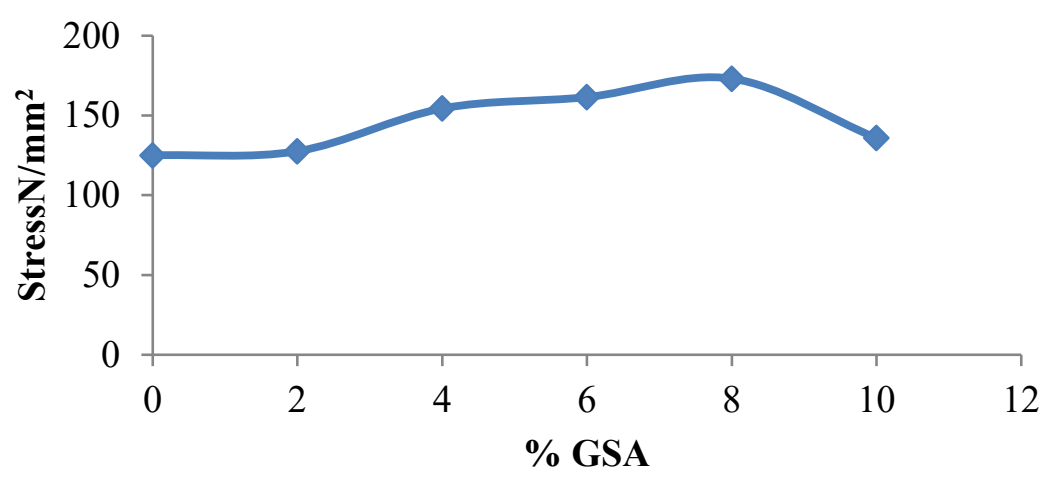

Figure 5:UCC \% comparison

Table 3 shows the CBR value of the soil with different percentages of GSA. The CBR value for a virgin soil specimen was 5.71 percent, but after combining 8\% GSA, it increased to 8.31 percent. The addition of GSA to the soil has resulted in a rise in CBR values. Thus the increase in value might be due to better interchange adhesion in the middle of the soil particles and the ash matrix interface.

\section{Conclusion}

It can be inferred from the experiments performed on soil specimens with Groundnut Shell Ash that GSA can be used as a natural reinforcing agent for the stabilization of soft clayey soils. The benefits of using GSA include its high durability to biodegradability, low cost, and strength properties. It's also good for keeping slopes stable. GSA may be used as a reinforcing material to help stabilize ductile pavements and reduce the thickness of the sub-grade. The following is the test result of our experiment. The soil specimen has a liquid cap of 58.4 percent. Highly compressible clay is the classification of the soil sample $(\mathrm{CH})$. The maximum dry density and optimum moisture content of virgin soil samples are $15 \%$ and $1.64 \mathrm{~g} / \mathrm{cc}$, respectively. The untreated soil sample's unconfined compressive strength (UCS) is $0.125 \mathrm{~N} / \mathrm{mm}^{2}$. The UCC intensity increases to $0.173 \mathrm{~N} / \mathrm{mm}^{2}$ when GSA is combined, but decreases as the percentage of GSA increases.

- A virgin soil specimen has a California Bearing Ratio (CBR) of 5.71. The CBR value increased to 8.31 percent when 8 percent GSA was added.

- The addition of GSA raised the soil specimen's intensity to 56.6 percent.

- The strength characteristics UCS of a virgin soil sample were $0.125 \mathrm{~N} / \mathrm{mm}^{2}$, but after adding $8 \%$ GSA, the UCS value rose to $0.173 \mathrm{~N} / \mathrm{mm}^{2}$.

- By combining 8\% GSA with the soil specimen, the optimum strength of the soil was achieved. 
- To avoid environmental issues such as open-air dumping, this can be used as a stabilization material in soil stabilization methods.

- Ash can alter the behavior of vast soil and correct it in a variety of geotechnical applications.

\section{References}

[1] Srinadh D, Praneeth P, Reddy D, Chamberlin K, Kumar NS. Stabilization of Black Cotton Soil using Lime and G.G.B.S (Ground Granulated Blast Furnace Slag) as an Admixtures. International Journal of Innovative Technology and Exploring Engineering (IJITEE). 2019; 9(2):2133-2136. https://doi.org/10.35940/ijitee.B7577.129219

[2] Atahu MK, Saathoff F, Gebissa A. Mechanical behaviors of expansive soil treated with coffee husk ash. Journal of Rock Mechanics and Geotechnical Engineering. 2018. Available from: https://doi.org/10.1016/j.jrmge.2018.11.004.

[3] Noorzad R, Motevalian S. Improvement of Clayey Soil with Lime and Industrial Sludge. Geotechnical and Geological Engineering. 2018;36(5):2957-2966. Available from: https://dx.doi.org/10.1007/s10706-018-0515-x.

[4] Dr.Robert, M.Brooks, A Soil stabilization with fly ash and rice husk ash (2009), International journal research and reviews in applied science, 2009;1(3):209-217

[5] Misra, A.Stabilization Characteristics of Clays Using Class C Fly Ash,Transportation Research Record, 2000, Transportation Research Board, National Research Council, Washington, D.C, 1611, 46-54. https://doi.org/10.3141/1611-06

[6] Sivapulliah P.V., Subba Rao K.S., and Gurumurthy, J.V., Stabilization of rice husk ash as a cushion below foundations on expansive soils, Ground Improvement, 2004, Vol. 8, No. 4, pp 137-149. https://doi.org/10.1680/grim.2004.8.4.137

[7] IS: 2720 (Part 5) - 1985 Indian Standard Code of practice for Determination of Liquid Limit.

[8] IS: 2720 (Part 6) - 1972 Indian Standard Code of practice for Determination of Plastic Limit.

[9] IS: 2720 (Part 8) - 1983 Indian Standard Code of practice for Determination of Modified Proctor Compaction parameters.

[10] IS: 2720 (Part 16) - 1979 Indian Standard Code of practice for Determination of California Bearing Ratio (CBR).

[11] IS: 2720 (Part 10) - 1991 Indian Standard Code of practice for Determination of Unconfined Compressive Strength of Soils (UCS). 